\begin{tabular}{lc}
\hline ISSN: & Joumal of \\
Print $-2277-078 X$ & Humanities, Social \\
Online $-2315-747 X$ & Sciences and Creative \\
O FUNAAB 2016 & Arts \\
\hline
\end{tabular}

\title{
PATTERN OF INTERNET USE AMONG YOUTHS IN SELECTED RURAL COMMUNITIES OF YEWA NORTH LOCAL GOVERNMENT AREA, OGUN STATE NIGERIA
}

\author{
K. 0. ADUBI AND 0. O. AKINBODE \\ Department of Home Science and Management (Extension and Rural Development) \\ Federal University of Agriculture, Abeokuta (FUNAAB)
}

Corresponding Author: kikeadubi@yahoo.com

Tel.: +2348037128294

\begin{abstract}
Youths living in rural communities have limited access to internet resources. Majority who have access to it have used it for limited purposes. The study investigated pattern of internet use among youths in the study area. Multi-stage sampling technique was used to select 245 youths for the study. Questionnaire was used for data collection. Data were analysed using descriptive and inferential statistics. Result showed more males used internet more than female (i.e 73.5\% and 26.5\%) respectively. Many of them (86.4\%) were within ages 18-22, above average were Christians (69.4\%) while the remaining were Muslims respectively. Their variations in their use of mobile platforms and applications are as follows: $82.9 \%$ used 2 go, $42.4 \%$ used facebook, $54.3 \%$ used SMS, while $8.2 \%$ used it for online transactions like purchase of products. Ranking their frequent usage, 2 go ranked highest followed by SMS among others. It was found there existed a significant association between respondents' age and pattern of internet use. It was established that youths in the communities used the internet for various purposes ranging from social to economic and religious purposes.
\end{abstract}

Keywords: Pattern, Internet Use, Youths, Rural Communities, Nigeria.

\section{INTRODUCTION}

The Nigerian National Y outh Policy (2001) defines youth as comprising all young people between the ages 18 and 35 years who are citizens of the Federal Republic of Nigeria. In addition, the African Youth Charter, which Nigeria ratified in 2009, defines youth as those aged 15 to 35 . However, the earlier stated 18-35 years was adopted for this study. Youths make up a significant portion of the workforce in both rural and urban communities. They have assumed wider community development roles through formation of youth associations
(Adesope, Agumagu, and Nwankwo, 2007). Internet has a value when it becomes accessible and usable especially among youths of the present generation. Therefore, usability and effectiveness of information largely depends on the access to information. Momodu (2002) reported that rural populations in Nigeria have restricted access to information on the internet, though it is a vital necessity for development and civilization.

Through communication, information that usually takes many days or weeks to disseminate now takes seconds or minutes. It is now possible for people especially youths to make 
interpersonal communication with others to get desired information as quickly as possible from other areas of the country or from other countries with the use of social media without leaving their immediate environment (Laittos Projects World, 2013).

\section{General U se of the Internet}

The internet has become a prime venue for social interaction (O 'keeffe, 2011). Through e-mail, chat room, instant messaging, newsgroups and other means, people are sharing aspects of their daily lives, talking about interests with likeminded others, and keeping in touch with family and friends. Social interaction has become the primary use of home computers (Moore, 2000). In the midst of all this social activities, people are forming relationships with those whom they meet on the Internet- especially those with whom they interact on a regular basis.

In many if not most ways, social interaction on the Internet resembles that in traditional, face-to-face venues (McKenna and Bargh, 1999). Social media is a form of electronic communication which facilitates interaction based on certain interests and characteristics. Social media are media for social interaction, using highly accessible and scalable publishing techniques. Social media use web -based technologies to transform and broadcast media monologues into social dialogues (Laitto Projects World, 2013). Social media has four platforms: facebook, 2go, twitter and whatsapp. Facebook started as a local social network made for the students of Harvard. It was developed by a sophomore, Mark Zuckerberg. Facebook was actually made by hacking Harvard's data base containing identification images of students. The initial idea was actually to compare the faces of students with images of animals, for entertainment purposes. However, due to the potentially damaging contents of the site, the creators decided to put it down before it caught the attention of school authorities. Facebook has grown to become the biggest and most popular social networking site today with a population of above 500 million active users. (Facebook statistics, 2012).

Advancement in technology in this era has reshaped all human activities on earth to include communication. Social media is among the numerous means which the people interact and communicate online. In the past decades, people communicate and interact on face to face basis, businesses were done on one and one levels, but with the vast increase in gadgets available in the market, communication process had been made easy and businesses can also be transacted on the internet thereby improving individual socioeconomic development. Critically, millions of people especially youths have employed the use of internet resources as a means of getting connected to the internet and a way of interacting with friends. Social media such as facebook, 2go, twitter and others had made the communication process easier (Laitto Projects World, 2013).

\section{Problem Statement}

However, in most rural communities, it was observed that majority of youths lack technicality in using the internet as a means of incuring social and economic development. In view of this, the study was conceived to investigate on how youths living in rural communities particularly Yewa North Local Government Area of $O$ gun State use internet, what for and for which purpose?

The objective of the research is to investigate the pattern of usage of the internet by youths in the area. Specifically, the objectives are (1) to assess the regularity of internet use, (2) 
PATTERN OF INTERNET USE AMONG YOUTHS IN SELECTED RURAL COMMUNITIES OF ..

ranking of respondents by their pattern of use and (3) factors associated with internet use by the youths in the area.

\section{Research $\mathrm{H}$ ypotheses}

The following null hypotheses were tested for their significance

Hol: There is no significant association between respondents' sex and internet use.

$\mathbf{H}_{\mathbf{0 2}}$ : There is no significant association between respondents' age and internet use.

$\mathbf{H}_{\text {03: }}$ There is no significant association between respondents' marital status and Internet use.

\section{RESEARCH METHODOLOGY}

Multi-stage technique was used to select 245 youths in rural communities of Y ewa North Local Government Area of Ogun State. Stage 1: Random selection of 2 out of 5 divisions that constituted the Local Government. Stage 2: Random selection of one village each from the 2 divisions. Stage 3: Purposive sampling of all youths using internet which constituted the subjects for the study. Instrument used was questionnaire.

\section{Measurement of Variables}

Section B of the instrument consists of 12 items which described pattern of Internet use among the respondents. The 12 items were measured on a 3-point rating scale (Regularly, Occasionally and never). Each of the platforms used was measured on 1 per point giving a maximum of 12 points and minimum of 1 point. The respondents were ranked based on their score and hence were categorized into low users (1-4 points); average users (5-8 points); and high users (9 -12 points). To ensure validity and reliability of the instrument, contents validity was done and split-half method was used to generate Cronbach's Alpha reliability co- efficient of 0.73 . D ata were analyzed using descriptive statistics (such as frequency counts, percentages, mean, standard deviation and ranking), while inferential statistics (Chi-square) was used to test for relationship between variables.

\section{RESULTS \\ Table 1: Socio-Demographic Characteristics of the Respondents}

The result in Table 1 shows that $73.5 \%$ of the respondents were male while $26.5 \%$ were female. Majority of the respondents (86.4\%) were within the age bracket of 18-22 years, $9.2 \%$ within $23-28$ years, and $4.0 \%$ within 29 -35 years respectively with the mean score age of 20.38 years. As a matter of fact, $85.3 \%$ were single, $13.9 \%$ were married and $0.8 \%$ was divorced. As revealed in the Table, $80.8 \%$ were not employed, $11.0 \%$ were selfemployed and $8.2 \%$ were formally employed. It was also shown that $66.5 \%$ of the respondents were living with their parents, $15.1 \%$ with their relatives, $1.2 \%$ with their friends and $17.1 \%$ living alone. In considering their religion, $69.4 \%$ were Christians while 30.6\% were Muslims. Lastly, about 50\% of the respondents said they belong to youth association while $49.8 \%$ said they do not.

Result presented in Table 2 shows pattern of Internet use which cut across what youths living in rural communities use the internet for social purposes as well as economic. The regularity of different platforms used by the youths showed Twitter and e-mailing as those not used while majority (82.9\%) of the youths regularly use 2 go platform to communicate with their friends on common happening in the community and some use it as an avenue to gossip. It is also one of the social networking services that enable users to send and read text based messages of up to 140 characters. Also, 54.3\% had regularly 
K. O.ADUBI AND O.O.AKINBODE

used their devices for the purpose of send- the respondents had regularly used their deing Short Message Services (SMS), $42.4 \%$ of vices to assess facebook.

RESULTS

Table 1: Socio-D emographic Characteristics of the Respondents

\begin{tabular}{|c|c|c|c|c|}
\hline Variables & Frequency & Percentages & Mean & Std. D \\
\hline \multicolumn{5}{|l|}{$\overline{\mathrm{Sex}}$} \\
\hline Male & 180 & 73.5 & & \\
\hline Female & 65 & 26.5 & & \\
\hline \multicolumn{5}{|l|}{ Age } \\
\hline $18-22$ & 212 & 86.4 & & \\
\hline $23-28$ & 23 & 9.2 & 20.38 & 3.205 \\
\hline $29-35$ & 10 & 4.0 & & \\
\hline \multicolumn{5}{|l|}{ Religion } \\
\hline Christianity & 170 & 69.4 & & \\
\hline Islam & 75 & 30.6 & & \\
\hline \multicolumn{5}{|c|}{ Marital Status } \\
\hline Single & 209 & 85.3 & & \\
\hline Married & 34 & 13.9 & & \\
\hline Divorced & 2 & 0.8 & & \\
\hline \multicolumn{5}{|c|}{ Employment Status } \\
\hline Self employed & 27 & 11.0 & & \\
\hline Employed & 20 & 8.2 & & \\
\hline Not employed & 198 & 80.8 & & \\
\hline \multicolumn{5}{|c|}{ Level of E ducation } \\
\hline Primary & 11 & 4.5 & & \\
\hline Secondary & 216 & 88.2 & & \\
\hline Tertiary & 18 & 7.3 & & \\
\hline Others & 0 & 0.0 & & \\
\hline \multicolumn{5}{|c|}{ Person Lived with } \\
\hline Parents & 163 & 66.5 & & \\
\hline Relatives & 37 & 15.1 & & \\
\hline Friends & 3 & 1.2 & & \\
\hline Alone & 42 & 17.1 & & \\
\hline \multicolumn{5}{|c|}{ Belonging to Youth Association } \\
\hline Yes & 123 & 50.2 & & \\
\hline No & 122 & 49.8 & & \\
\hline
\end{tabular}

J. Hum. Soc. Sci. \& Crtv. Arts 2016, 11 (1\& 2): 117 - 126 
PATTERN OF INTERNET USE AMONG YOUTHS IN SELECTED RURAL COMMUNITIES OF ..

Table 2: Pattern of Internet use among Y ouths in the Area

\begin{tabular}{|c|c|c|c|c|c|c|c|c|c|}
\hline \multirow{2}{*}{ Internet Resources } & \multicolumn{2}{|c|}{ Regularly } & \multicolumn{2}{|c|}{ Occasionally } & \multicolumn{2}{|c|}{ Never } & \multirow[t]{2}{*}{ Mean } & \multirow[t]{2}{*}{ Std. D } & \multirow[t]{2}{*}{ Rank } \\
\hline & Freq & $\%$ & Freq & $\%$ & Freq & $\%$ & & & \\
\hline \multicolumn{10}{|l|}{ Social Purposes } \\
\hline E-mail & 34 & 13.9 & 32 & 13.1 & 179 & 73.1 & 1.41 & .723 & 8 \\
\hline Facebook & 104 & 42.4 & 104 & 42.4 & 37 & 15.1 & 2.28 & .712 & 3 \\
\hline Twitter & 26 & 10.6 & 41 & 16.7 & 178 & 72.6 & 1.38 & .671 & 9 \\
\hline $2 g o$ & 203 & 82.9 & 27 & 11.0 & 15 & 6.1 & 2.77 & .550 & 1 \\
\hline Whatsapp & 44 & 18.0 & 51 & 20.8 & 150 & 61.2 & 1.57 & .781 & 7 \\
\hline Internet games & 50 & 20.4 & 69 & 28.2 & 126 & 51.4 & 1.70 & .791 & 6 \\
\hline $\begin{array}{l}\text { D ownload music/ } \\
\text { movies }\end{array}$ & 87 & 35.5 & 110 & 44.9 & 48 & 19.6 & 2.16 & .728 & 4 \\
\hline Make voice calls & 83 & 33.9 & 40 & 16.3 & 122 & 49.8 & 1.85 & .903 & 5 \\
\hline SMS & 133 & 54.3 & 67 & 27.3 & 45 & 18.4 & 2.35 & .776 & 2 \\
\hline \multicolumn{10}{|c|}{ Economic Purposes } \\
\hline Buy products & 20 & 8.2 & 19 & 7.8 & 206 & 84.1 & 1.24 & .593 & 11 \\
\hline Advertise Skills & 15 & 6.1 & 15 & 6.1 & 215 & 87.7 & 1.19 & .527 & 12 \\
\hline $\begin{array}{l}\text { Search for custom- } \\
\text { ers }\end{array}$ & 22 & 9.0 & 17 & 6.9 & 206 & 84.1 & 1.25 & .610 & 10 \\
\hline
\end{tabular}

\section{Ranking of Internet use by the Respondents}

In ranking the respondents according to popular usage, 2go was ranked highest which indicated that many of the respondents used their mobile devices to access 2 go platform which serve as a major means of communication in rural communities. The application (2go application) work with java small phones which are affordable and accessible by low income earners unlike smart phones or tablets that are sold at exorbitant rates which may not be affordable and accessible by the audience in question. The use of devices for SMS comes next to it which obtained the second position in the ranking which majority whether in rural or urban send to express their thought and feelings. Third on the ranking is using their devices to access facebook which is among the social medium platform available for use, the last on the ranking is using their devices to advertise skills on the internet.

Based on the score obtained by the individ- ual respondent on their frequency of internet use, they were categorised into three (low, average and high internet users respectively). The categorisation was represented by the figure shown below :

\section{Figure 1: Categonization of the respon- dents based on level of frequency of Internet use}

In view of result presented in Table 2, a three point rating score was used to categorize the respondents into three stages: high users, average users and low users of the Internet. An individual respondent who score between 1-4 points was categorized as low internet user; 5-8 points average internet user; and 9-12 points high internet user respectively. Based on the information provided, $122(49.8 \%)$ of the respondents were found to be low internet users, 110 (44.9\%) average internet users, and 13 (5.3\%) high internet users respectively. 


\section{Categorization of the respondents based on level of frequency of Intemet use}

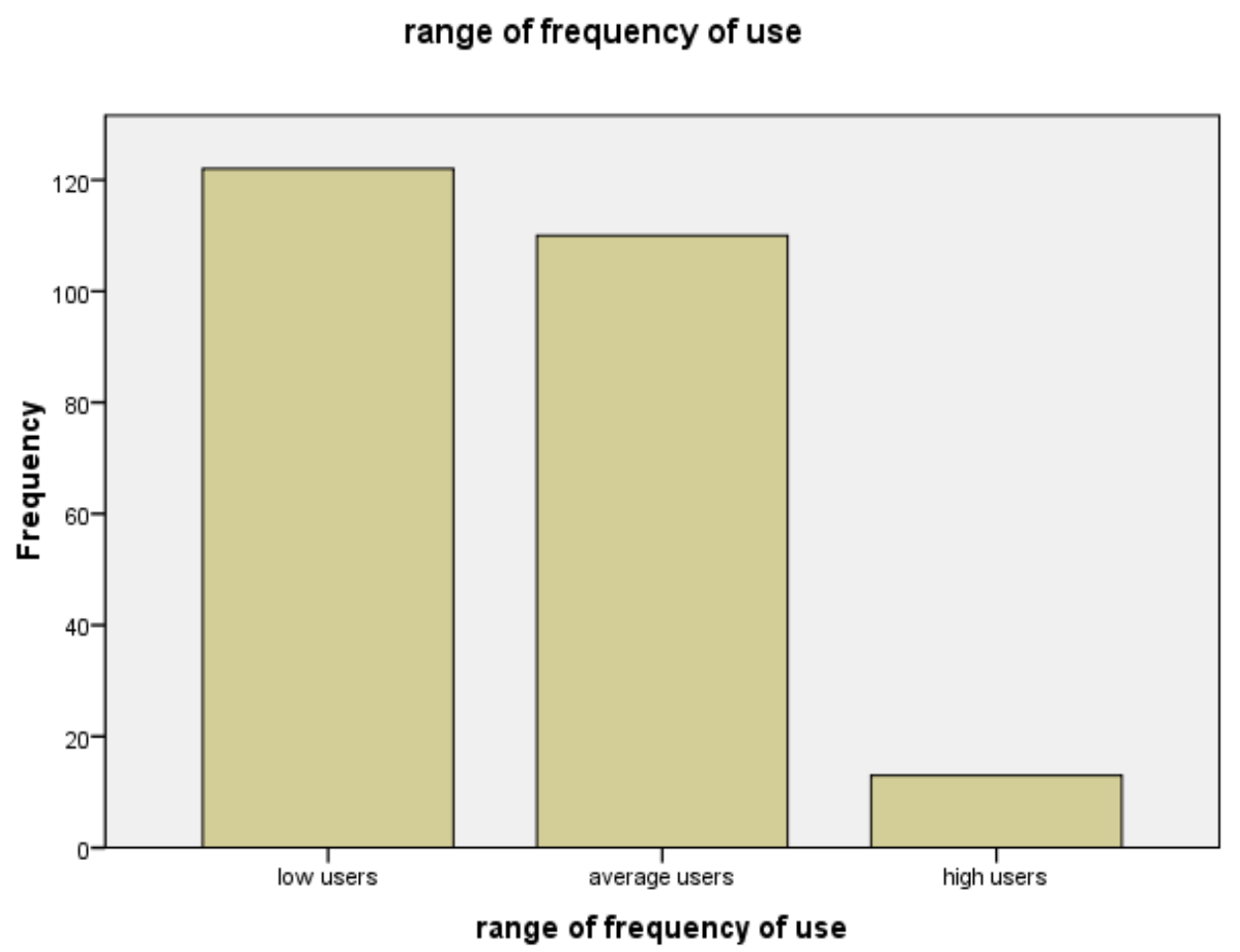

Table 3: Result of Chi-square analysis showing the relationship between respondents' Sex and their use of Intemet

\begin{tabular}{llll}
\hline Sex & & \multicolumn{2}{c}{ Frequency of Intemet Use } \\
\hline \multirow{2}{*}{ Male } & High Users & Average Users & Low Users \\
Female & $12(4.9 \%)$ & $85(34.7 \%)$ & $83(33.9 \%)$ \\
\hline
\end{tabular}

$\chi^{2}=5.033 ; \mathrm{df}=1 ; \mathrm{p}=0.08$

Decision criterion is reject null hypothesis greater than 0.05 . Result shows that there when $\mathrm{p}<0.05$ was no significant relationship between respondents' sex and frequency of Internet Table 3 shows the test of association be- use. This means that whether an individual is tween respondents' sex and frequency of a male or female, has no influence on beInternet use. The null hypothesis was ac- coming high, average or low user of the cepted because the $\mathrm{p}$-value obtained was internet i.e the helpline services apart from 
PATTERN OF INTERNET USE AMONG YOUTHS IN SELECTED RURAL COMMUNITIES OF ..

reducing information gaps also serve in $\mathbf{H}_{\mathbf{0 2}}$ : There is no significant association besharing community information. tween respondents' age and frequency of internet use.

Table 4: Result of Chi-square analysis showing the relationship between respondents' age and their use of Intemet

\begin{tabular}{llll}
\hline Age & \multicolumn{2}{l}{ Frequency of Intemet Use } & \\
\hline & High Users & Average Users & Low Users \\
$18-22$ & $7(2.9 \%)$ & $97(39.6 \%)$ & $108(44.1 \%)$ \\
$23-28$ & $3(1.2 \%)$ & $11(4.5 \%)$ & $9(3.7 \%)$ \\
$29-35$ & $3(1.2 \%)$ & $2(0.8 \%)$ & $5(2.0 \%)$ \\
\hline
\end{tabular}

$\chi^{2}=17.733 ; \mathrm{df}=2 ; \mathrm{p}=0.001$

Decision criterion is reject null hypothesis when $\mathrm{p}<0.05$

Table 4 shows the result of the association between respondents' age and their frequency of internet use. The null hypothesis was rejected because the $p$-value obtained was less than 0.05. Result shows that there was a significant association between respondents' age and frequency of Internet use. This implies that an individual who is between the ages of 18-22 uses the internet more. These are adolescents who are more inclined to innovations and modern technology.

$\mathbf{H}_{\text {03: }}$ There is no significant association between respondents' marital status and frequency of internet use.

Table 5: Result of Chi-square analysis showing the relationship between respondents' marital status and their use of Intemet

\begin{tabular}{llll}
\hline Marital Status & \multicolumn{3}{c}{ Frequency of Intemet Use } \\
\hline Single & High Users & Average Users & Low Users \\
Married & $10(4.1 \%)$ & $93(38.0 \%)$ & $106(43.3 \%)$ \\
Divorced & $3(1.2 \%)$ & $16(6.5 \%)$ & $15(6.1 \%)$ \\
\hline
\end{tabular}

$\chi^{2}=1.316 ; \mathrm{df}=2 ; \mathrm{p}=0.86$

Decision criterion is reject null hypothesis when $\mathrm{p}<0.05$

The result presented in Table 5 shows the test of association between respondents' marital status and their frequency of Internet use. As shown in Table 5, the null hypothesis was accepted because the $p$-value obtained was greater than 0.05 . Result shows that there was no significant relationship between respondents' marital status and frequency of Internet use. This implies that whether an individual is single, married or divorced, has no effect on frequency of Internet use. 


\section{DISCUSSION}

The focus of the study was to investigate pattern of Internet use among youths in selected rural communities of Y ewa North LGA, Ogun State, Nigeria. Majority 180 $(73.5 \%)$ of the respondents were male and $212(86.4 \%)$ fell within the age bracket of 18-22 which was known to be the active age range of individual in life time. Findings further revealed that $198(80.8 \%)$ of the respondents were not employed and reason for this might be due to the environment in which the study was carried out where there were limited white collar jobs and another reason could be due to the fact that many of them are still in secondary school. Also, many of the subjects $163(66.5 \%)$ were found to be in the custody of their parents and a little above average $123(50.2 \%)$ belong to youths' association in the study area. Burell (2008) and Hudson (2006) argued that mobile phones improve the productivity of individuals within resourceconstrained environments.

Pattern of Internet use among youths in rural communities of Yewa North Local G overnment cut across what they access on the internet and frequency of its access.

According to Harande (2009), internet has become a prime venue for social interaction. For example, it was discovered that many (Table 2) of the youths have used 2go platform to communicate and interact with their friends on common happening in the community and some use it as an avenue to gossip. This agreed with Goodman (2007) finding that there were links between mobile usage, rural communities and social capital in his study communities in South Africa and Tanzania and that mobile facilitated three types of social capitals: as an amenity and shared commodity; to mediate strong links with family and friends and other community members; and to mediate weak links with individuals outside the community, e.g business men, government officials, tradesmen, etc. Also, above average (see Table 2) have used their devices for the purpose of sending Short Message Services (SMS), and some have used it to assess facebook- a platform which can be used to send facial expression and pictures to loved ones and peers.

Other purposes for which it has been used is similar to those identified by Robson and Fumoto (2009) who stated that Facebook is popular as it enables one to interact with friends on a wide scale. Findings further identified factors that could have influence on the use of internet by the respondents. Such factors include sex in terms of male and female, age in number and marital status in terms of single or married. Study established a significant association between respondents' age and their frequency of internet use and this implies that an individual in his or her early youthful age (18-22 years) is likely to use the internet more than someone in his late youthful age (29-35 years). In real sense or by observation, many of the aged in both rural and urban do not often seen using the computers to access the internet except few who are educated particularly, among academicians or bankers.

\section{CONCLUSION}

The study has established the fact that youths who had access to the internet in rural communities had used their devices for various purposes which the researchers classified as social and economic purposes. On the regularity of internet platform used, 2go was ranked first and the last was using the internet to advertise skills which was ranked twelfth. In general, findings shows that youths in the study area tend to use their de- 
vices more for social purposes than they do for economic purposes which may be due to technicality and other factors.

\section{RECOMMENDATIONS}

In view of the investigation to pattern of Internet use among youths in the study area, the following recommendations are made:

- Specialised training should be organised to educate youths in using their devices for further social and economic purposes.

- Awareness of the importance of Internet should be stressed to rural youths most especially female youths as only a few of them participated in the study.

- Youth mobilizers and change initiators could take advantage of this to sensitize youths in the area on matters that affects them.

\section{REFERENCES}

Adesope, 0. M, Agumagu, A. C, Nwankwo, C. (2007). Importance of youths in commuity deddopment: perspetives for agialtural extension In: Adeyanju P. 2014. Social Media and the Nigerian Y ouths. G reenBiro.

Burell, J. (2008). Liveihoods and the Mdbile phome in Rural Uganda Gramen Foundation, USA. Retrieved from http:/ / www.grameenfoundation applab.org/ section/ ethnographic research.

Facebook Statistics (2012). Social TimesSocial Media Statistics and Facts 2012.

Goodman, J. (2007). Linking Mdbile Phone onneship and use to Soial Capital in Rural Sath Africa and Tanzania: Moving the Debate Forward The Vodafone Policy Paper Series,
No 3. Vodafone Research.

Harande, Y. I. (2009). Information Services for Rural Community D evelopment in Nigeria. Library Philosophy and Practice (e joumal). Paper 271. Available online at http:/ / digitalcommons.unl.edu/

libphilprac/ 271

Hudson, H. (2006). From Rural Village to Global Village: Telecommunications for D evelopment in the Information Age. C. T: Lawrence Erlbaum, D anbury.

Laittosprojects (2013). Impact of Facdbook and 2go as an Effective Interpersonal Media of Communication New Mass Communication Project. O sun State.

Mckenna, K. Y. A., \& Bargh, J. A. (1999). Causes and Consequences of Social Interaction on the Internet: A Conceptual Framework. Media psydhdogy, 1, 249-269.

Momodu, M. O. (2002). Information needs and information seeking behaviour of rural dwellers in Nigeria: a case study of Ekpoma in Esan West local government area of Edo State, Nigeria. Library Review, 51 (8), 406 410.

Moore, D.W. (2000. February 23). American say Internet makes their lives better ( $\mathrm{On}$ line), Gallup News Service. Available at http:/ / www.gallup.com/ poll/ releases/ pr000223.asp

0'Keeffe, L. (2011). The Impact of Social Media on Children, Adolescents, and Families. Jaumal of American acadamy of Pediatrics 127 (4), 800-804.

Robson, S. and Fumoto, H. (2009). Practitioners' Experiences of Personal OwnerJ. H um. Soc. Sci. \& Crtv. Arts 2016, 11 (1 \& 2): 117 - 126 125 
K.O.ADUBI AND 0.O.AKINBODE

ship and Autonomy in their Support for IssuesinEarly Childhood, 10 (1), 43-54.

Young Children's Thinking. Contemporary

(Manuscript reeiveet 10thAugust, 2016; accepted 23rdeJune, 2017 